Review

\title{
Sulfenic acids as reactive intermediates in xenobiotic metabolism
}

\author{
Daniel Mansuy*, Patrick M. Dansette* \\ Laboratoire de Chimie et Biochimie Pharmacologiques et Toxicologiques, UMR 8601 CNRS, Université Paris Descartes, 45 rue des Saints-pères, 75270 Paris Cedex 06, France
}

\section{A R T I C L E I N F O}

\section{Article history:}

Available online xxxx

\section{Keywords:}

Sulfenic acid

Xenobiotics

Metabolism

Cytochrome P450

Oxidation

Reactive metabolites

\begin{abstract}
A B S T R A C T
Sulfenic acid reactive intermediates are formed during the oxidation of cysteine residues of proteins and play key roles in enzyme catalysis, redox homeostasis and regulation of cell signalling. However few data are presently available on the formation and fate of sulfenic acids as reactive intermediates during the metabolism of xenobiotics. This article is a review of the xenobiotic metabolism situations in which the intermediate formation of a sulfenic acid has been reported. Formation of these intermediates has been either proposed on the basis of the isolation of products possibly deriving from sulfenic acids or shown after trapping of the sulfenic acid by specific nucleophiles. This review indicates the different mechanisms by which a sulphur-containing xenobiotic can be metabolized with the intermediate formation of a sulfenic acid. It also indicates the different possible fates of these sulfenic acids that have been reported in the literature. Finally, it discusses the possible implications of the formation of xenobioticderived sulfenic acid reactive metabolites in pharmacology and toxicology.
\end{abstract}

(c) 2010 Elsevier Inc. All rights reserved.

\section{Introduction}

Sulfenic acid reactive intermediates are formed during the oxidation of cysteine residues of proteins [1-6]. This oxidation of cysteines can be reversed through the action of specific enzymes such as thioredoxins. Thus, oxidation of specific protein cysteine residues may operate like a switch through the activation or deactivation of their cellular functions [5,6]. Some of those proteins are involved in signal transduction and many data suggest that sulfenic acids play key roles in enzyme catalysis, redox homeostasis and regulation of cell signalling [5,6].

Sulfenic acids often undergo further oxidations to more stable oxidized metabolites such as sulfinic and sulfonic acids (Eq. (1)).

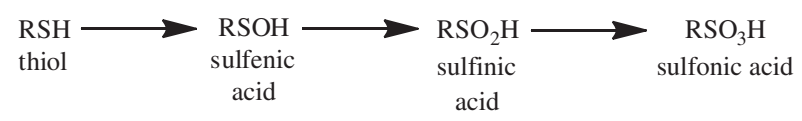

Cysteine sulfenic acids are highly reactive intermediates that could not be observed as such in most cases. However, in rare cases, they can be isolated and stabilized within particular protein micro-environments, and have been observed by X-ray crystallography and NMR spectroscopy [5]. In most cases, the formation of protein cysteine sulfenic acids has been shown through the detection of their stable adducts with specific nucleophiles. The most widely used trapping agent for sulfenic acids is dimedone, a C-nucleophile that rapidly reacts with the electrophilic sulphur

\footnotetext{
* Corresponding authors. Fax: +33 142868387 (D. Mansuy).

E-mail addresses: daniel.mansuy@parisdescartes.fr (D. Mansuy), patrick. dansette@parisdescartes.fr (P.M. Dansette).
}

atom of sulfenic acids with formation of stable adducts involving a C-S bond (Fig. 1) [7,8]. Another trapping agent often employed for the detection of protein sulfenic acids is 4-chloro-7-nitrobenzo-2-oxa-1,3-diazole (NBD-Cl) ${ }^{1}$ (Fig. 2) [5,9].

Few data are presently available on the formation and fate of sulfenic acid reactive intermediates during the metabolism of xenobiotics [10-12]. As reactive electrophilic species they can covalently bind to cell nucleophiles such as proteins and be involved in pharmacological or toxicological effects of the parent xenobiotic. This article is a review of the situations in which the intermediate formation of a sulfenic acid has been either proposed or shown in the metabolism of xenobiotics. It indicates the different mechanisms by which a sulphur-containing xenobiotic can be metabolized with the intermediate formation of a sulfenic acid. It also indicates the different possible fates of these sulfenic acids that have been reported in the literature. Finally, it discusses the possible implications of the formation of xenobiotic-derived sulfenic acid reactive metabolites in pharmacology and toxicology.

\section{Different ways of formation of sulfenic acid reactive Intermediates during xenobiotic metabolism}

\section{Formation of sulfenic acids by oxidation of a thiol function}

Thiols, RSH, are good substrates of cytochrome P450- and flavin-dependent monooxygenases [10,13]. Thiols exhibiting a marked nucleophilic character of their S-atom are generally good substrates of flavin-dependent monooxygenases, whereas the less

\footnotetext{
${ }^{1}$ Abbreviations used: NBD-Cl, 4-chloro-7-nitrobenzo-2-oxa-1,3-diazole; GSH, glutathione; Ticlid, Ticlopidine; TZD, thiazolidinedione; CYP102, cytochrome P450 $\mathrm{BM}_{3}$.
} 

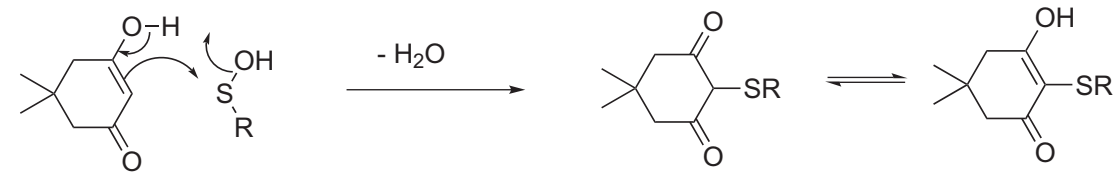

Fig. 1. Trapping of sulfenic acids with dimedone.<smiles>[R]O[SH+]([R])O</smiles>

Fig. 2. Trapping of sulfenic acids by 4-chloro-7-nitrobenzo-2-oxa-1,3-diazole.

marked the nucleophilic character of the S-atom, the greater the probability of its oxidation by cytochromes P450 [10]. It is generally admitted that monooxygenase-catalyzed oxidation of thiols first leads to a sulfenic acid intermediate which can be further oxidized to the corresponding sulfinic acid and then to a sulfonic acid. However, sulfenic acids are electrophilic intermediates that rapidly react with the parent thiol RSH or another thiol present in the medium, such as glutathione (GSH), with formation of disulfides RSSR or RSSG [10] (Fig. 3).

Spironolactone 1(Fig. 4) is an antimineralocorticoïd, diuretic drug containing a thioester $\mathrm{SCOCH}_{3}$ function. The major metabolic route of $\mathbf{1}$ is a hydrolytic deacetylation leading to the corresponding thiol 2. In the presence of liver microsomes, $\mathrm{NADPH}$ and $\mathrm{O}_{2}$, the thiol function of $\mathbf{2}$ is oxidized with formation of the sulfinic and sulfonic acid metabolites $\mathbf{4}$ and $\mathbf{5}$, that have been identified by HPLC-MS by comparison with authentic chemically synthesized compounds [14]. In the presence of GSH, another metabolite, the glutathionyl-spironolactone mixed disulfide $\mathbf{6}$ is formed [15] (Fig. 4). Moreover, during cytochrome P450-dependent oxidation of 2 , some cytochromes $\mathrm{P} 450$ are inactivated in a suicidal manner $[14,16]$. Metabolites $\mathbf{4}, \mathbf{5}$ and $\mathbf{6}$ have been proposed to derive from a common precursor, sulfenic acid $\mathbf{3}$ that may either react with GSH with formation of $\mathbf{6}$ or undergo further oxidation with formation of 4 and 5. Inactivation of cytochromes P450 during oxidation of 2 has been related to the formation of the electrophilic sulfenic acid 3, or of a thiyl radical that could be an intermediate in the P450catalyzed oxidation of thiol $\mathbf{2}$ into sulfenic acid 3 [14].

Formation of sulfenic acids during the oxidative metabolism of thioesters $\mathrm{R}-\mathrm{CO}-\mathrm{S}-\mathrm{R}^{\prime}$

\section{Plausible pathway for sulfenic acid formation from metabolic oxidation of thioesters}

The high-valent iron-oxo active species involved in the catalytic cycle of dioxygen activation by cytochromes $\mathrm{P} 450$ should be able to transfer its oxygen atom to the S atom of thioesters RCOSR' with formation of the corresponding thioester S-oxides RCOSOR'. Actually, as we will see later, the formation of such a RCOSOR' species, with $\mathrm{R}=\mathrm{N}\left(\mathrm{C}_{2} \mathrm{H}_{5}\right)_{2}$ and $\mathrm{R}^{\prime}=\mathrm{CH}_{3}$, has been shown during the oxidation of a disulfiram metabolite by liver microsomes [17] (Eq. (2)).

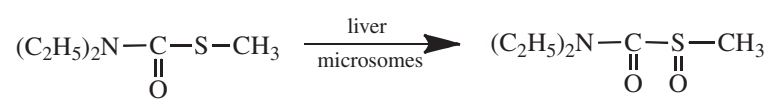

In general, the carbon atom of the carbonyl group of these thioester S-oxides should be highly electrophilic and should rapidly react with nucleophiles. Its reaction with $\mathrm{H}_{2} \mathrm{O}$ should lead to a hydrolytic cleavage of the $\mathrm{CO}-\mathrm{SO}$ bond with formation of $\mathrm{RCOOH}$ and a sulfenic acid intermediate R'SOH (Fig. 5). In the particular case of the disulfiram metabolite, the presence of the electrondonating substituent $\mathrm{N}\left(\mathrm{C}_{2} \mathrm{H}_{5}\right)_{2}$ should decrease the reactivity of the carbonyl group of $\left(\mathrm{C}_{2} \mathrm{H}_{5}\right)_{2} \mathrm{NCOSOCH}_{3}$ towards $\mathrm{H}_{2} \mathrm{O}$, explaining the relative stability and successful isolation of this oxidized metabolite [17].

Recent evidence for the formation of sulfenic acid reactive intermediates during the metabolism of the anti-thrombotic drugs ticlopidine, clopidogrel and prasugrel

Ticlopidine (Ticlid) $\mathbf{7 a}$ and clopidogrel (Plavix, Iscover) 7b (Fig. 6) are anti-thrombotic prodrugs of the tetrahydrothienopyridine series that must be metabolized in vivo into the corresponding pharmacologically active thiols $\mathbf{9 a}$ and $\mathbf{9 b}$, respectively, to exert their activity as antagonists of the platelet receptor P2Y12 [1820]. Ticlopidine was introduced to the market in 1979 for prevention of thrombotic stroke. Clopidogrel was first launched in 1998 in the USA and in 1999 in Europe, for the reduction of atherosclerotic problems in patients with stroke, myocardial infraction or periphenal arterial disease. Their metabolic activation occurs in two steps that are catalyzed by cytochromes P450 $[18,19]$. The first step is a classical cytochrome P450-dependent hydroxylation of the thiophene ring by NADPH and $\mathrm{O}_{2}$ leading to thiolactone metabolites $\mathbf{8 a}$ and $\mathbf{8 b}$, respectively [21-23] (Fig. 6). It is mainly catalyzed by CYP 2C19 and CYP 2B6 in the case of 8a and by CYP 2C19, CYP $1 \mathrm{~A} 2$ and CYP 2B6 in the case of $\mathbf{8 b}$ [24]. The second step leading to the pharmacologically active thiols $\mathbf{9 a}$ and $\mathbf{9 b}$ also requires the involvement of a cytochrome P450-catalyzed oxidative step with consumption of NADPH and $\mathrm{O}_{2}$ (CYP 3A4, CYP 2B6, CYP 2C9 and CYP 2C19 are mainly involved in oxidation of $\mathbf{8 b}$ ) [24,25]. It has been recently shown that this step is an oxidative cleavage of the

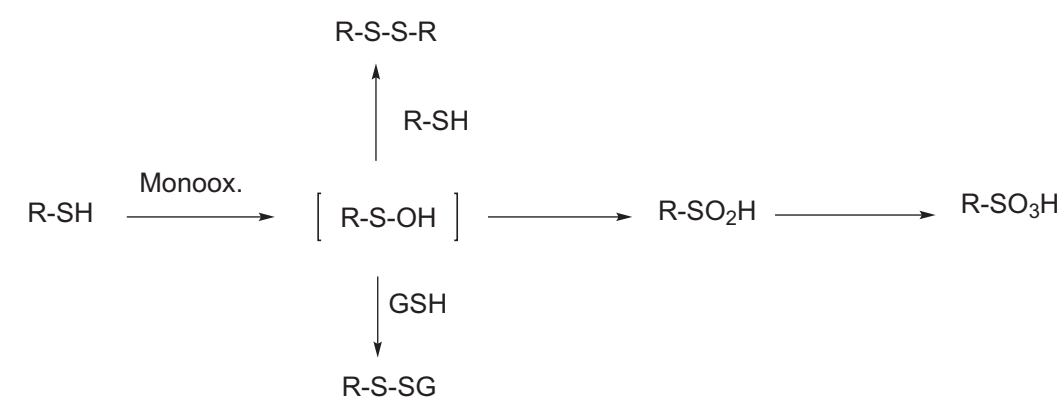

Fig. 3. Different possible products formed upon metabolism of xenobiotic thiols. 
<smiles>CC(=O)SC1CC2=CC(=O)CCC2(C)C2CCC3(CCC(=O)O3)C3CCC12C3</smiles>

spironolactone<smiles>CC1CC(S(=O)(=O)O)C(C)C(C)C1C</smiles>

$\underline{5}$<smiles>CC1CC(S(=O)(=O)O)C(C)C(C)C1C</smiles>

$\underline{4}$<smiles>CC1C[C@H](S)C(C)C(C)C1C</smiles><smiles>CC1C[C@H](SO)C(C)C(C)C1C</smiles>

GSH<smiles>CC1CC(S(=O)(=O)O)C(C)C(C)C1C</smiles>

$\underline{6}$

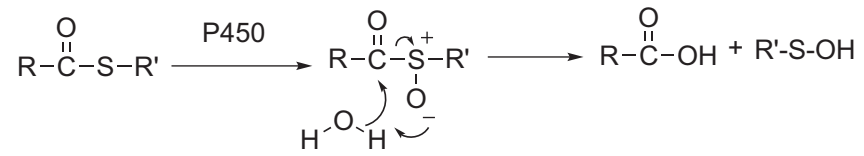

Fig. 5. Plausible mechanism for sulfenic acid formation during oxidative metabolism of thioesters. thiolactone ring of metabolite $\mathbf{8}$ leading to the formation of reactive sulfenic acid intermediates $\mathbf{1 0}$ [26]. These intermediates have been trapped by dimedone during oxidative metabolism of thiolactones $\mathbf{8}$ by rat and human liver microsomes or by several recombinant human liver cytochromes P450, namely CYP 3A4, CYP 2C8, CYP 2C9, CYP $1 \mathrm{~A} 2$ and CYP 2B6. The corresponding dimedone adducts $\mathbf{1 1}$ have been completely characterized by NMR spectros-

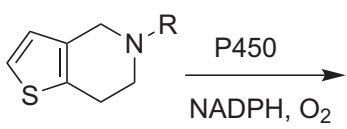

$\underline{7}$<smiles>[R]N1CCC2SC(=O)C=C2C1</smiles>

8<smiles>[R]N1CCC2C(=CC(=O)[SH]2(=O)O)C1</smiles>

$\mathbf{b}, \mathbf{R}=$

$$
\text { COOMe }
$$

$\mathbf{a}, \mathbf{R}=$<smiles>Cc1ccccc1Cl</smiles>

Ticlopidine
$\mathrm{HC}$<smiles>Cc1ccccc1Cl</smiles>

Clopidogrel

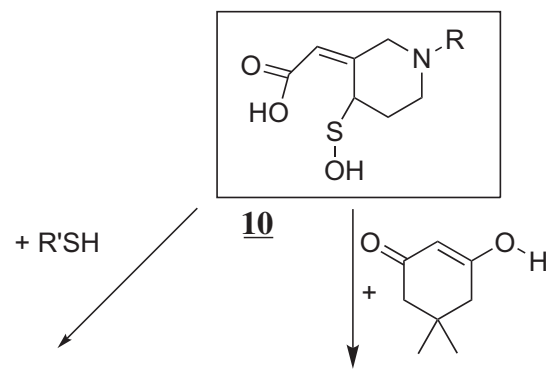<smiles>[R15]CC(C)[C@H]1CCN([R])C/C1=C/C(=O)O</smiles>

$\underline{9}$<smiles>[R1]S[C@H]1CCN([R])C/C1=C/C(=O)O</smiles>

$\underline{12}$

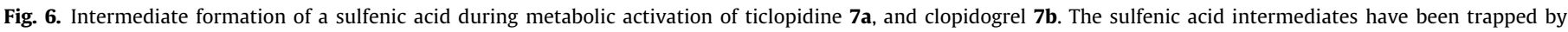
dimedone or thiols ( $\mathrm{R}$ 'SH=mercaptoethanol, $\mathrm{N}$-acetylcysteine and glutathione). 
copy and mass spectrometry [26]. Sulfenic acid intermediates have also been trapped by thiols added to the incubation medium, such as mercapto-ethanol, $\mathrm{N}$-acetylcysteine and glutathione. The resulting mixed disulfides 12 (Fig. 6) have been characterized by mass spectrometry [26]. In the presence of a large excess of R'SH thiol, disulfides $\mathbf{1 2}$ are further converted to the pharmacologically active metabolites $\mathbf{9}[18,19,24]$ whose formation was shown in vivo in man [24]. These data [26] have provided the first evidence for the formation of sulfenic acid reactive intermediates in the metabolism of tetrahydrothienopyridine anti-thrombotic drugs, and, in a more general manner for the formation of a sulfenic acid in cytochrome P450-catalyzed oxidative cleavage of thioesters, according to Fig. 5. They have also suggested a first detailed pathway for the formation of active thiols 9 in the metabolism of ticlopidine and clopidogrel. This pathway would involve two successive cytochrome P450-dependent monooxygenations leading to sulfenic acids $\mathbf{1 0}$, followed by a reduction of $\mathbf{1 0}$ to pharmacologically active $\mathbf{9}$ due to two successive reactions of a thiol, which should be GSH in vivo, with intermediate formation of a disulfide 12 (Fig. 6).

Prasugrel (Effient) $\mathbf{1 3}$ is the newest member of the class of tetrahydrothienopyridine anti-thrombotic produgs. It is also an irreversible inhibitor of the platelet receptor P2Y12, after metabolic conversion in vivo to a pharmacologically active 4-mercapto-3piperidinyliden acetic acid derivative $\mathbf{1 5}$, that is analogous to $\mathbf{9}$ [27,28] (Fig. 7). Metabolic conversion of prasugrel to $\mathbf{1 5}$ involves two enzymatic reactions: (i) the hydrolysis of its ester function leading to thiolactone $\mathbf{1 4}$, which seems to be mainly catalyzed by the $\mathrm{hCE}_{2}$ enzyme in man [29], and (ii) the oxidative cleavage of the thioester bond of $\mathbf{1 4}$ with the eventual formation of $\mathbf{1 5}$, which is catalyzed by cytochromes P450 3A4, 2B6, 2C9 or 2C19 in man [24]. As in bioactivation of ticlopidine and clopidogrel, it has been shown that this cytochrome P450-catalyzed oxidative cleavage of the thioester bond of thiolactone $\mathbf{1 4}$ led to the formation of an intermediate sulfenic acid $\mathbf{1 6}$ [30,31]. Formation of $\mathbf{1 6}$ was demonstrated by trapping it with dimedone in incubations of prasugrel with rat or human liver microsomes in the presence of NADPH [31]. The resulting stable adduct $\mathbf{1 7}$ was isolated and completely characterized by mass spectrometry and detailed NMR spectroscopy [31]. In the presence of thiols such as GSH $[30,31]$ or 2-nitro-5-thiobenzoic acid [30], sulfenic acid 16 was trapped with formation of mixed disulfides such as 18. In the presence of the water-soluble phosphine, $\mathrm{P}\left(\mathrm{CH}_{2} \mathrm{CH}_{2} \mathrm{COOH}\right)_{3}$, that has been previously used to reduce sulfenic acids [32], incubation of prasugrel with liver microsomes and NADPH led to thiol 15 [31]. These data indicate that sulfenic acid $\mathbf{1 6}$ can be efficiently trapped by $\mathrm{C}$-nucleophiles such as dimedone, $\mathrm{S}$-nucleophiles such as GSH or simpler thiols, and P-nucleophiles such as $\mathrm{P}\left(\mathrm{CH}_{2} \mathrm{CH}_{2} \mathrm{COOH}\right)_{3}$. A possible mechanism for the last reaction is shown in Fig. 8 [31]. Trapping of sulfenic acid intermediates by dimedone during metabolism of xenobiotics in vitro appears as the best method of detection of such intermediates because the corresponding adducts, that involve a stable C-S bond, are generally stable in the metabolic incubation media. Trapping of sulfenic acids by the water-soluble phosphine $\mathrm{P}\left(\mathrm{CH}_{2} \mathrm{CH}_{2} \mathrm{COOH}\right)_{3}$ seems to be a clean method for the eventual formation of the thiol metabolites derived from sulfenic acids reduction. These thiol metabolites themselves can be trapped by N-ethyl-maleimide to form thioether adducts such as $\mathbf{2 0}$ that are more stable than their thiol precursors under metabolic conditions [31] (Fig. 7).

Trapping of sulfenic acids by thiols such as GSH leads to mixed disulfides such as $\mathbf{1 8}$. However, thiols are less specific trapping agents of sulfenic acids than dimedone, because the obtained mixed disulfide adducts can be formed by various pathways that do not involve the intermediate formation of sulfenic acids. Moreover, mixed disulfides are much less stable adducts than the sulfenic acid-dimedone adducts, as they are very reactive towards thiols that could be present in the reaction media. This is illustrated by the results obtained during microsomal oxidations of ticlopidine, clopidogrel or prasugrel in the presence of GSH in excess which

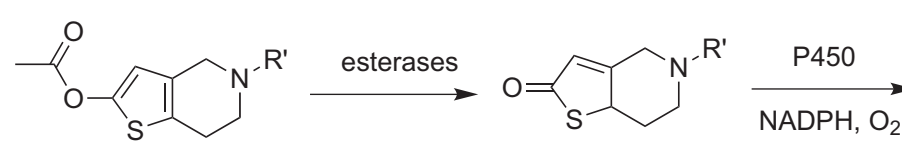

13 Prasugrel<smiles>[R]#CC(C(=O)C1CC1)c1ccccc1F</smiles>

$\underline{14}$<smiles>[R]N1CCC(SS(=O)(=O)O)C(=CC(=O)O)C1</smiles>

$\underline{18}$

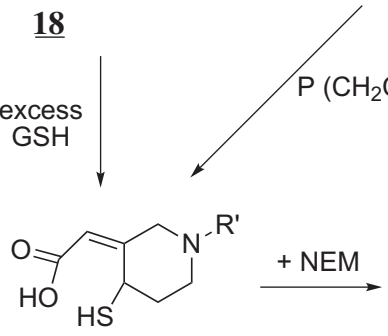

$\underline{15}$<smiles>OCCO</smiles><smiles>[R]N1CCC(SO)C(=CC(=O)O)C1</smiles><smiles>[R]N1CCC(SC2CC(=O)N(CC)C2=O)C(=CC(=O)O)C1</smiles>

19<smiles>[R]N1CCC2C(=CC(=O)[S+]2[O-])C1</smiles><smiles>[R]N1CC[C@H](SC2=C(O)CC(C)(C)CC2=O)/C(=C\C(=O)O)C1</smiles>

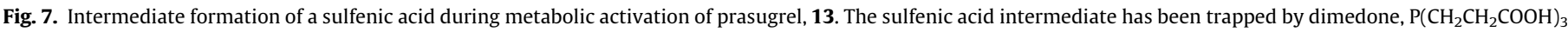
or GSH. NEM = N-ethylmaleimide. 


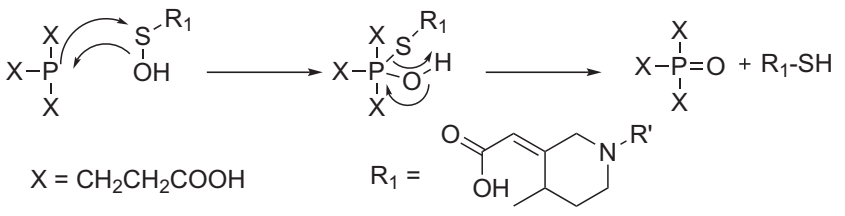

Fig. 8. Possible mechanism for the reduction of sulfenic acids by phosphines.

showed that the intermediate disulfide glutathionyl adducts, 12 and 18, further react with GSH with the eventual formation of thiols $\mathbf{9}$ and 15, respectively [26,30,31]. Anyway, trapping of sulfenic acids by GSH is an interesting reaction that provides cystathionyl mixed disulfides which could be intermediates and/or metabolites in the metabolic transformation of thiolactones such as $\mathbf{8}$ and $\mathbf{1 4}$ into thiols 9 and 15, respectively.

Coming back to the oxidative cleavage of thiolactones such as 14 leading to sulfenic acids, it is likely that the first step of this reaction is a transfer of the oxygen atom of the high-valent ironoxo $(\mathrm{Fe}=\mathrm{O})$ species of cytochrome $\mathrm{P} 450$ to the thiolactone sulphur atom, leading to a highly reactive thiolactone S-oxide $\mathbf{1 9}$ (Fig. 7). Three pathways could be considered for the following step, the hydrolytic cleavage of the CO-SO bond of this thiolactone S-oxide (Fig. 9)): (a) a nucleophilic attack of $\mathrm{H}_{2} \mathrm{O}$ on its carbonyl group leading directly to $\mathbf{1 6}$ after protonation of the SO moiety, (b) a rearrangement of thiolactone S-oxide $\mathbf{1 9}$ coming from an intramolecular attack of the $\mathrm{O}^{-}$atom on the $\mathrm{CO}$ group, with formation of a sixmembered cyclic sulfenic ester 19' (Fig. 9), followed by reaction of $\mathrm{H}_{2} \mathrm{O}$ on the carbonyl group, or (c) the same rearrangement but followed by reaction of $\mathrm{H}_{2} \mathrm{O}$ on the electrophilic sulphur atom of the six-membered sulfenic ester. In pathways a) and b) one of the two oxygen atoms of the carboxylate group of $\mathbf{1 6}$ is coming from $\mathrm{H}_{2} \mathrm{O}$, whereas, in pathway c), one of the oxygen atoms of the carboxylate group of 16 should come from $\mathrm{O}_{2}$ during P450-dependent sulfoxidation of 14. Incubation of prasugrel 13, with rat liver microsomes in the presence of $\mathrm{NADPH}$, dimedone and ${ }^{18} \mathrm{O}_{2}$ led to adduct 17 , that has not incorporated ${ }^{18} \mathrm{O}$ atoms $(<5 \%)$. Identical incubations under ${ }^{16} \mathrm{O}_{2}$ but in $\mathrm{H}_{2}{ }^{18} \mathrm{O}$ showed a major incorporation of ${ }^{18} \mathrm{O}$ (>85\%) into the dimedone adduct. These experiments [31] indicated that the oxygen atom incorporated into adduct $\mathbf{1 7}$ came from water and not from $\mathrm{O}_{2}$, which ruled out pathway (c) of Fig. 9 for

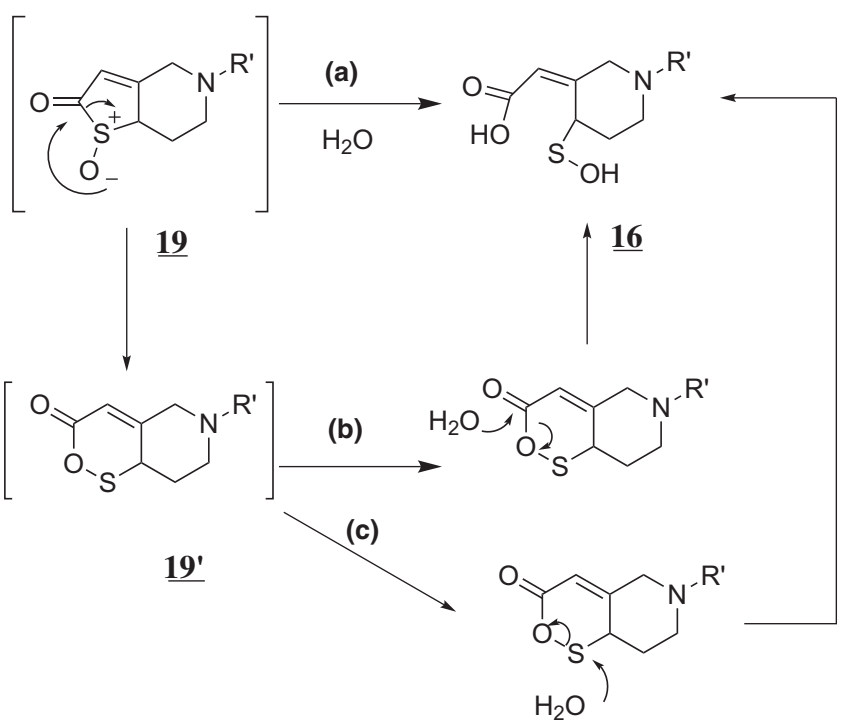

Fig. 9. Possible pathways for the formation of a sulfenic acid derived from prasugrel from the corresponding thiolactone S-oxide. sulfenic acid formation. Thus, formation of sulfenic acid $\mathbf{1 6}$ should involve a nucleophilic attack of $\mathrm{H}_{2} \mathrm{O}$ on the electrophilic carbonyl group of either thiolactone S-oxide $\mathbf{1 9}$ or its rearranged sulfenic acid ester product 19'. Very similar results were obtained in the same labelling experiments of incubation of $\mathbf{8 b}$, the thiolactone metabolite of clopidogrel with rat liver microsomes, NADPH, and dimedone (P.M. Dansette, S. Thébault and D. Mansuy, unpublished results).

Indirect evidence for the formation of sulfenic acid intermediates during the metabolism of glitazones

Glitazones are thiazolidinedione (TZD)-containing drugs widely used in the treatment of type-2 diabetes. Several in vitro and in vivo studies have shown that the TZD ring of various glitazones such as troglitazone 21a, MK-0767 21b, and MRL-A 21c (Fig. 10), was subject to an oxidative metabolism resulting in its opening with formation of reactive metabolites [33-34]. A detailed study of the metabolites derived from the oxidation of the TZD ring of 21c by monkey liver microsomes in the presence of NADPH showed the formation of several compounds that should derive from sulfenic acid 22c [34] (Fig. 11). This includes glutathionyl adduct 23c, that could result from the attack of the sulphur atom of GSH on the sulphur atom of 22c, thiol 24c, and sulfinic acid 25c. It was proposed that the two last compounds could derive from a disproportionation of sulfenic acid 22c, according to Fig. 12, and that thiol 24c could also come from reduction of $22 \mathrm{c}$ by NADPH or of $23 \mathrm{c}$ by GSH in excess [34].

This mechanism proposed for the oxidative cleavage of the TZD ring of glitazones is very similar to that described above for the oxidative cleavage of the lactone ring of ticlopidine, clopidogrel and prasugrel. In both cases, the reaction should start with an Soxidation of the ring followed by a fast hydrolytic opening upon attack of $\mathrm{H}_{2} \mathrm{O}$ on the very electrophilic carbon of the intermediate. In the case of glitazones, another possible fate of this intermediate has been proposed [34], the $\beta$-elimination of the $\mathrm{NH}$ proton leading to a very reactive isocyanate that would react with $\mathrm{H}_{2} \mathrm{O}$ to give the corresponding amide after loss of $\mathrm{CO}_{2}$ (Fig. 11). The fates of the intermediate sulfenic acids were similar for the two series of drugs, with the formation of the corresponding thiols and glutathione mixed disulfide adducts in both cases. The main difference was concerned with the formation of a sulfinic acid derived from glitazones $[33,34]$ that has not been observed so far in the case of the tetrahydrothienopyridine drugs.

Another mode of metabolic activation of the TZD ring was proposed on the basis of the detection and characterization by HPLCMS of another GSH adduct 26a upon oxidation of troglitazone by rat liver microsomes [35] (Fig. 13). Formation of this adduct was interpreted as a reaction of GSH on an intermediate sulfenium

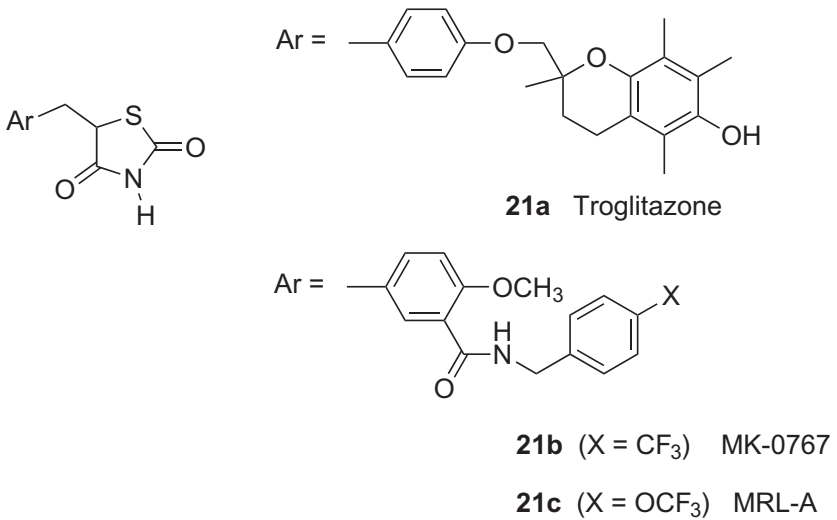

Fig. 10. Formula of glitazones MK-0767, MRL-A and troglitazone. 
<smiles>O=C1NC(=O)C(CBr)S1</smiles>

$\underline{21 c}$<smiles>CCC1C(=O)NC(=O)S1(C)[O-]</smiles><smiles>CCC</smiles><smiles>O=C=NC(=O)C(CBr)SO</smiles><smiles>NC(=O)C(CBr)S[Ge]</smiles>

$\underline{23 c}$<smiles>NC(=O)C(CBr)SCCS</smiles>

$\underline{24 c}$<smiles>C[14C](=O)[14C](=O)[14C](=O)[O-]</smiles><smiles>NC(=O)C(CBr)SO</smiles><smiles>NC(=O)C(CBr)S(=O)(=O)O</smiles>

$\underline{25 c}$

Fig. 11. Proposed formation of a sulfenic acid intermediate during metabolic activation of 21c.<smiles>[R]C(C(N)=O)[S+](O)O[Si](CC)O[Hg]</smiles><smiles>[R]C(S)C(N)=O</smiles>

Fig. 12. Proposed mechanism of disproportionation of sulfenic acid 22c.

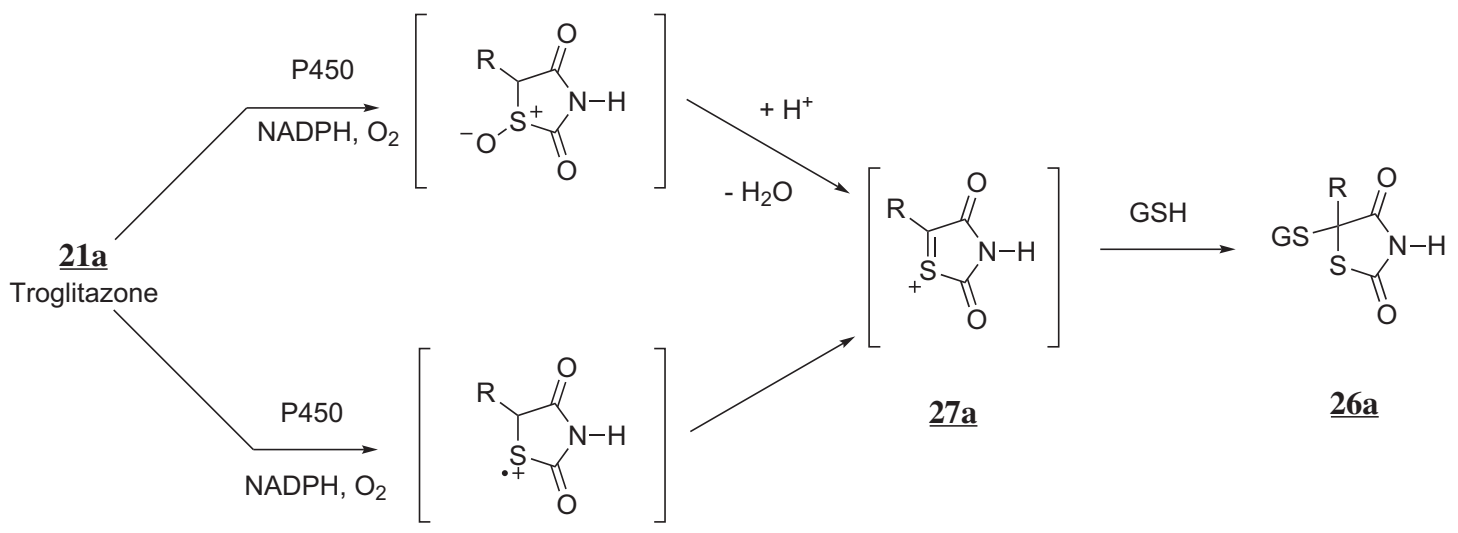

$\underline{28 a}$

Fig. 13. Mechanism proposed for the formation of a glutathione adduct upon S-oxidation of troglitazone.

ion, 27a, that could come either from a loss of $\mathrm{H}_{2} \mathrm{O}$ from the S-oxide intermediate or from the sulphur radical-cation 28a.

Possible formation of sulfenic acid intermediates during the metabolism of thio- and dithio-carbamates related to disulfiram

Disulfiram (Antabuse) (Fig. 14), that is used in the clinical treatment of alcoholism, exerts its pharmacological effects as an inhib- itor of liver mitochondrial alcohol dehydrogenase. These inhibitory effects are due to electrophilic metabolites of disulfiram [17,3638]. Thiocarbamate $\mathbf{2 9}$ is a metabolite of disulfiram involving a $\mathrm{CO}-\mathrm{S}$ bond, that undergoes an S-oxidation, as the thioesters discussed above (see general Fig. 5). The resulting metabolite 30 that involves a $\mathrm{CO}-\mathrm{SO}$ bond is the equivalent of the intermediate Soxide formed upon metabolic activation of thioesters related to 


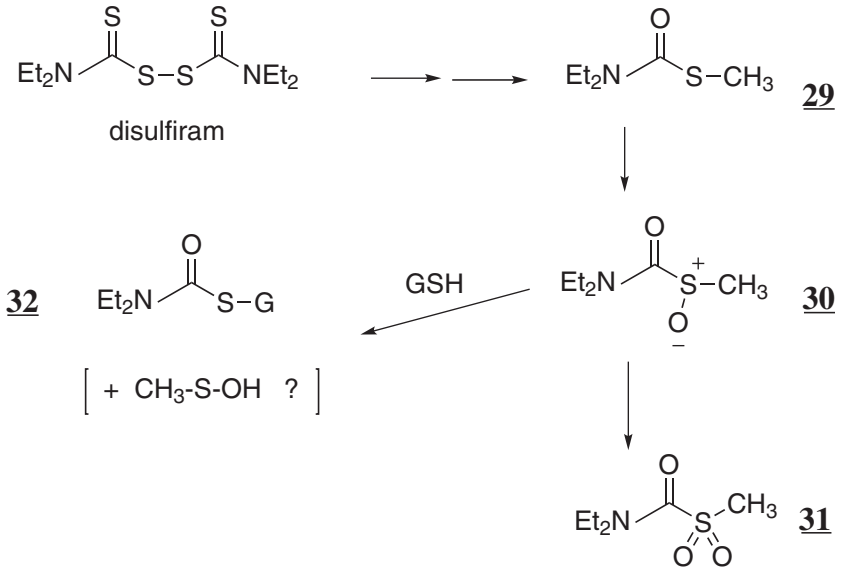

Fig. 14. Metabolic activation of disulfiram leading to a thioester and its various electrophilic metabolites.

anti-thrombotic tetrahydrothienopyridines and to glitazones. However, in this case, metabolite $\mathbf{3 0}$ is stable enough to be isolated; its formation has been completely established, and an authentic sample of $\mathrm{N}, \mathrm{N}$-diethylthiolcarbamate $\mathrm{S}$-oxide, $\mathbf{3 0}$, has been synthesized from oxidation of $\mathbf{2 9}$ with one equivalent of $\mathrm{NaIO}_{4}$ [17]. Thiols such as GSH or $\mathrm{N}$-acetylcysteine react with the electrophilic carbonyl carbon of $\mathbf{3 0}$ with formation of thiol adducts such as the acylglutathione compound 32 that was detected in the bile of rats treated with disulfiram [36,37]. In this reaction of GSH with 30, formation of $\mathbf{3 2}$ should be accompanied with the formation of methyl sulfenic acid (Fig. 14). However, the formation of this sulfenic acid remains to be established, and the irreversible inhibition of alcohol dehydrogenase by disulfiram metabolites is believed to derive from reactions of this protein with electrophilic metabolites such as $\mathbf{3 0}, \mathbf{3 1}$, and their equivalents involving a $\mathrm{C}=\mathrm{S}$ moiety $[36,37]$.

Certain thio- and dithio-carbamate herbicides and pesticides, which also inhibit alcohol dehydrogenase in vivo, have been shown to form electrophilic S-oxidized metabolites similar to those proposed for disulfiram [39-41].

Possible formation of sulfenic acid intermediates during irreversible inhibition of cytochrome P450 $\mathrm{BM}_{3}$ by fatty acid thioesters

Fatty diacid monoethyl thioesters are irreversible inhibitors for cytochrome P450 $\mathrm{BM}_{3}$ (CYP102), that exploit the $\omega-2$ oxidation specificity of this cytochrome [42]. Catalytic oxidation of the monoethyl thioesters of dodecanedioic and hexadecanedioic acids results in cytochrome $\mathrm{P}_{450} \mathrm{BM}_{3}$ inactivation and formation of the parent diacids as metabolites [42]. GSH prevents this inactivation of the enzyme, and it has been proposed that an electrophilic metabolite is responsible for enzyme inactivation. Thioester Soxide 33 has been proposed as such an electrophilic metabolite (Fig. 15). Reaction of its carbonyl carbon with $\mathrm{H}_{2} \mathrm{O}$ should lead to the eventual diacid metabolite, whereas its reaction with a nucleophilic residue of the protein should be at the origin of enzyme inactivation. During these reactions, the SEt part of $\mathbf{3 3}$ should be released as the EtSOH sulfenic acid. However, formation of this sulfenic acid remains to be demonstrated.

Other examples of oxidative metabolism of thioesters with intermediate formation of reactive thioester $S$-oxides

The herbicidal compound dithiopyr 34 contains two thioester functions (Fig. 16). Its transformation by rat liver microsomes leads to the corresponding carboxylic acids such as $\mathbf{3 5}$ as main metabolites [43]. This transformation of its thioester functions into carboxylic acids has been found to be catalyzed by monooxygenases, and not esterases. Microsomal metabolism of dithiopyr also leads to a glutathione conjugate $\mathbf{3 6}$ (Fig. 16) globally resulting from the replacement of the $\mathrm{SCH}_{3}$ group of a dithiopyr thioester function with the SG group of glutathione. On the basis of those results, the mechanism of transformation of the thioester functions of dithiopyr into carboxylic acid functions was proposed to proceed through a monooxygenase-catalyzed S-oxidation followed by a hydrolysis of the very reactive $\mathrm{CO}-\mathrm{SO}$ bond of the intermediate 37 (Fig. 16).

The anti-inflammatory glucocorticoid drug, fluticazone propionate 38, also involves a thioester function. Its main metabolite in man is the carboxylic acid $\mathbf{3 9}$ formally deriving from the hydrolysis of its thioester function [44] (Fig. 17). However, it was also found in that case that this reaction involved an oxidation mainly catalyzed by the cytochromes P450 of the 3A subfamily [44].

Another anti-inflammatory steroid drug involving a thioester function, tixocortol pivalate $\mathbf{4 0}$ (Fig. 17), led to several metabolites in man, such as $\mathbf{4 1}$ and $\mathbf{4 2}$, resulting from a cleavage of its thioester bond and its replacement with $\mathrm{S}-\mathrm{CH}_{3}$ and $\mathrm{SO}_{2} \mathrm{CH}_{3}$ functions [45]. The detailed mechanisms of the cleavage of the thioester function of fluticazone propionate and tixocortol pivalate have not been determined. However, a mechanism similar to that found in the case of dithiopyr would involve a monooxygenase-catalyzed S-oxidation of their thioester function followed by a hydrolysis of the $\mathrm{CO}-\mathrm{SO}$ bond of the intermediate S-oxide. The sulfenic acid metabolites resulting from this hydrolysis have not been looked for. Formation of such a sulfenic acid intermediate in the case of tixocortol would explain the formation of the thioether and sulfone metabolites from further reactions of reduction, methylation and S-oxidation, that have been previously found during metabolism of prasugrel and glitazones $[24,33]$.

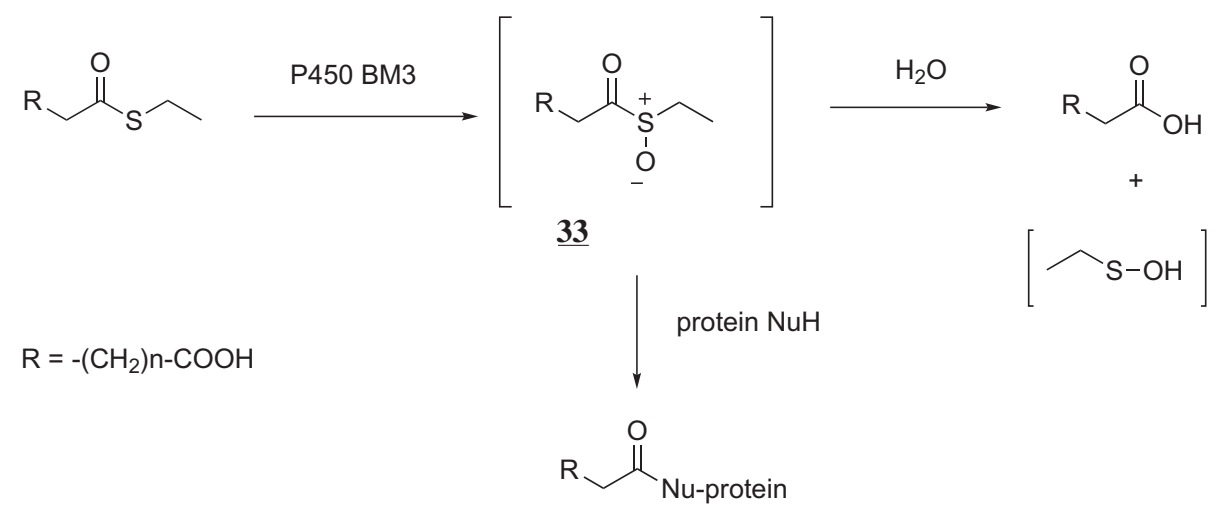

Fig. 15. Mechanism proposed for the metabolic activation of fatty acid thioesters used as irreversible inhibitors of $\mathrm{P}_{450} \mathrm{BM}_{3}$. 
<smiles>CSC(=O)c1c(C(F)(F)F)nc(C(F)(F)F)c(C(=O)SC)c1CC(C)C</smiles>

dithiopyr $\underline{34}$<smiles>CSC(=O)c1c(C(F)(F)F)nc(C(F)(F)F)c(C(=O)O)c1CC(C)C</smiles>

$\underline{35}$
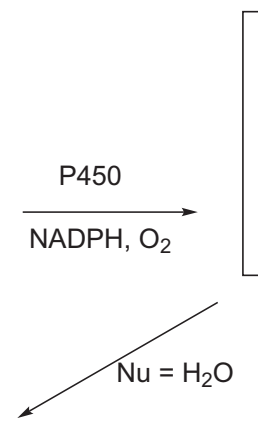<smiles>COC(=O)c1c(C(F)F)nc(C(F)(F)F)c(C(=O)SC)c1CC(C)C</smiles>

$\underline{37}$ $\mathrm{Nu}=\mathrm{GSH}$<smiles>CSC(=O)c1c(C(F)(F)F)nc(C(F)(F)F)c(C(=O)[SeH])c1CC(C)C</smiles>

$\underline{36}$

Fig. 16. Formation of a reactive intermediate during metabolic transformation of the thioester functions of dithiopyr into carboxylic acid functions.

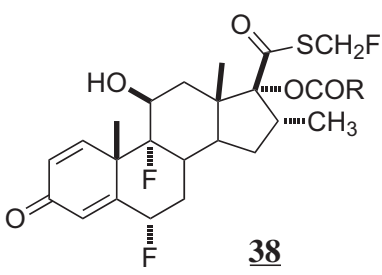

$\mathrm{R}=$ Ethyl Fluticazone propionate

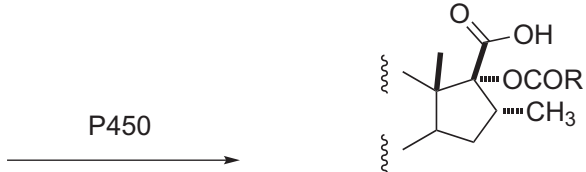

$\underline{39}$<smiles>CC(C)(C)C(=O)SCC(=O)[C@]1(O)CCC2C3CCC4=CC(=O)CCC4(C)C3C(O)C[C@]21C</smiles>

40<smiles>CSCC(=O)[C@]1(O)CCC(C)C1(C)C</smiles>

$\underline{41}$<smiles>[Y]C1CCC(O)(C(=O)CS(C)(=O)=O)C1(C)C</smiles>

$\underline{42}$

Tixocortol pivalate

Fig. 17. Metabolism of the thioester functions of fluticasone propionate and tixocortol pivalate in man.

\section{Formation of sulfenic acids from metabolism of sulfoxides}

Formation of sulfenic acids during metabolic activation of $\mathrm{H}^{+} / \mathrm{K}^{+}$ATPase inhibitors such as omeprazole

Drugs, such as omeprazole, esomeprazole and lansoprazole, that are used to treat gastreso-phageal reflux disease, act as inhibitors of the proton transport by the gastric $\mathrm{H}^{+} / \mathrm{K}^{+}$ATPase. Acutally, these compounds are produgs that must be activated in situ into reactive metabolites able to bind covalently to cysteine residues of $\mathrm{H}^{+} / \mathrm{K}^{+}$ATPase [46-48]. The mechanism proposed for this activation is shown in Fig. 18 in the case of omeprazole 43. According to this mechanism, this prodrug is activated under the acidic conditions of the stomach with intermediate formation of a spiro intermediate $\mathbf{4 4}$ that undergoes aromatization with cleavage of a $\mathrm{C}-\mathrm{S}$ bond and formation of sulfenic acid $\mathbf{4 5}$. This sulfenic acid, or sulfeneamide $\mathbf{4 6}$ that derives from its intramolecular reaction with a benzimidazole nitrogen atom, reacts with a cysteine of $\mathrm{H}^{+} / \mathrm{K}^{+}$ATP- ase to form a disulfide adduct $\mathbf{4 7}$. It is noteworthy that reactive electrophilic intermediates $\mathbf{4 5}$ and $\mathbf{4 6}$ are only formed in situ in close proximity of the target after protonation of $\mathbf{4 3}$ under the stomach acidic conditions.

Interestingly, a sulfenic acid intermediate would be formed during metabolism of pantoprazole $\mathbf{4 8}$, a proton pump inhibitor of the prazole series, from an addition-elimination reaction of GSH on the C-2 atom of the benzimidazole moiety of 48 (Fig. 19). Such a reaction should lead to sulfenic acid $\mathbf{5 0}$ and the glutathione conjugate 49. Another GSH conjugate and another intermediate sulfenic acid $\mathbf{5 2}$ would be formed from a nucleophilic attack of GSH on the activated benzylic $\mathrm{CH}_{2}$ group of pantoprazole, resulting in a cleavage of its $\mathrm{CH}_{2}$-SO bond and formation of a benzylic GSH adduct $\mathbf{5 1}$ and sulfenic acid $\mathbf{5 2}$ [49]. Actually, the two GSH adducts derived from pantoprazole, 49 and 51, were identified at the level of their further breakdown products [49]. 
<smiles>COc1ccc2[nH]c([SH]([O-])Cc3cc(C)c(OC)c(C)n3)nc2c1</smiles>

omeprazole $\underline{\mathbf{4 3}}$<smiles></smiles>

$\underline{46}$

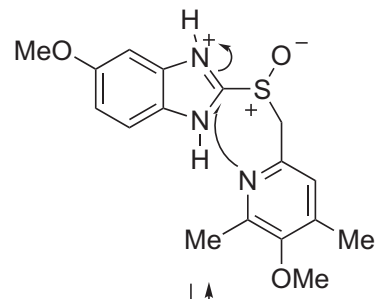<smiles>[C]1[C+]=CC=C1</smiles>

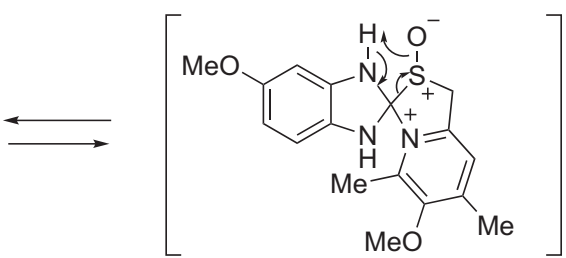

$\underline{44}$

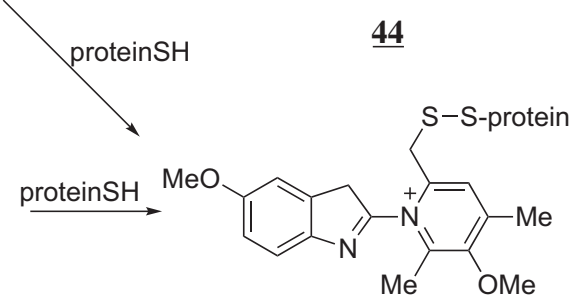

$\underline{47}$

Fig. 18. Proposed formation of a sulfenic acid during metabolic bioactivation of omeprazole.<smiles>CCS(C)(=O)(Cc1nc2ccc(OCF)cc2[nH]1)c1nccc(OC)c1OC</smiles>

pantoprazole

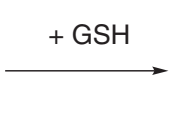

$\underline{48}$<smiles>COc1ccnc(CS)c1OC</smiles>

$\underline{51}$<smiles>COc1ccc2nc(SO)[nH]c2c1</smiles>

$\underline{52}$<smiles>[3H][13CH2][AsH3]</smiles><smiles>FCOc1ccc2nc([Se])[nH]c2c1</smiles><smiles>COc1ccnc(CSO)c1OC</smiles>

Fig. 19. Proposed formation of sulfenic acids during metabolism of pantoprazole.

Intermediate formation of a sulfenic acid in the metabolism of an allylic sulfoxide

Diallyl sulfide, a flavour component of garlic, is metabolized in rats into many compounds deriving from an initial S-oxidation followed by glutathione conjugation [50]. Reaction of diallyl sulfoxide $\mathbf{5 3}$ with GSH leads to two GSH conjugates, $\mathbf{5 4}$ and 55, and sulfenic acid 56. This sulfenic acid was not characterized as such, but its formation was supported by the isolation of allyl-SSG, 55, a product expected from reaction of $\mathbf{5 6}$ with GSH (Fig. 20).

\section{Conclusion}

Different chemical situations leading to sulfenic acid intermediates during xenobiotic metabolism, fate of these intermediates in biological media, and consequences of their formation in pharmacology and toxicology

From the presently available literature data concerning sulfenic acid formation during xenobiotic metabolism, that are described in the previous sections, it appears that such a formation was 


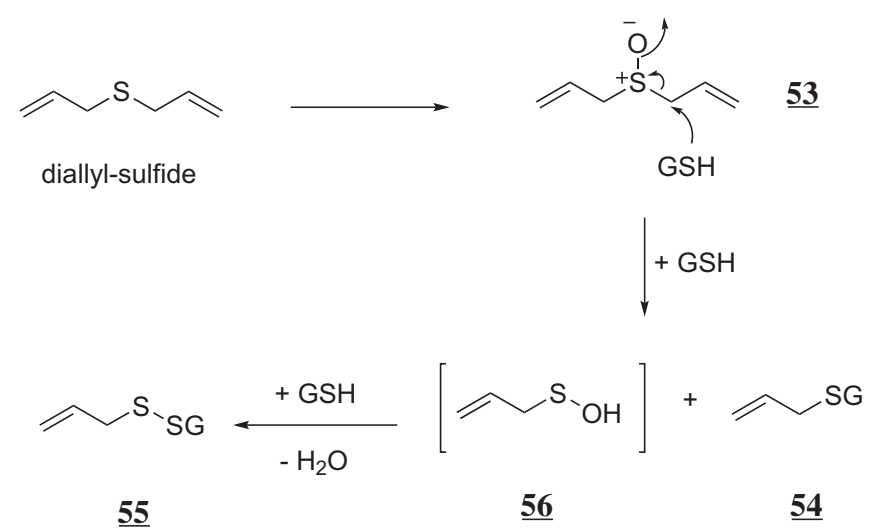

Fig. 20. Proposed formation of a sulfenic acid during metabolism of diallyl sulfide.

established by specific trapping in very few cases. Sulfenic acid formation was most often proposed on the basis of the isolation of metabolites that could derive from them, such as glutathionyl adducts RSSG, sulfinic and sulfonic acids $\mathrm{RSO}_{2} \mathrm{H}$ and $\mathrm{RSO}_{3} \mathrm{H}$, or thiols $\mathrm{RSH}$.

These literature data indicate that sulfenic acid formation during xenobiotic metabolism occurs in three chemical situations depending on the xenobiotic structure: (i) the S-hydroxylation of xenobiotics involving a thiol function, (ii) the S-oxidation of thioesters RCOSR' leading to an oxidative cleavage of their CO-S bond, and (iii) the cleavage of a $\mathrm{C}-\mathrm{S}$ bond of xenobiotics bearing a sulfoxide function, resulting from the attack of a nucleophile (GSH for instance) on an electrophilic carbon in $\alpha$-position of the SO function. Actually, if one excepts the S-hydroxylation of thiols, most of the above described (or proposed) sulfenic acid formations are derived from a common general reaction, the attack of a nucleophile $\left(\mathrm{H}_{2} \mathrm{O}\right.$ or GSH) on an electrophilic carbon in $\alpha$-position of a sulfoxide function that is present either in the starting xenobiotic or in a metabolite. This nucleophilic attack results in the cleavage of the carbon-SO bond with formation of a sulfenic acid (Fig. 21A). This electrophilic carbon may be an allylic carbon in the case of diallylsulfoxide (Fig. 20), a benzylic carbon in the case of pantoprazole (Fig. 19), a carbonyl carbon in the case of the S-oxide metabolites of thioesters (Figs. 6 and 7), and a $\mathrm{C}=\mathrm{N}^{+}$carbon in the case of omeprazole (Fig. 18). However, it is noteworthy that in the case of sulfenic acid formation from the oxidation of some thioesters, another mechanism proposed for the cleavage of a C-SO bond was based on the loss of a $\beta$-proton (relative to the SO function) resulting in a 1,2-elimination of RSOH (Fig. 21B). Such a mechanism has been proposed for sulfenic acid formation from glitazones [34] (Fig. 11) and fatty acid thioesters [42].

The possible fates of sulfenic acid intermediates RSOH formed during xenobiotic metabolism that can be derived from the presently available literature data are summarized in Fig. 22. Most often, they derive from reactions with nucleophiles. Reactions with thiols R'SH lead to mixed disulfides RSSR' or to the thiol RSH derived from $\mathrm{RSOH}$ if $\mathrm{R}$ 'SH is used in excess. In that regard, the most relevant reactions in xenobiotic metabolism are those involving $\mathrm{GSH}$, the detection of glutathionyl adducts RSSG being a first indication of intermediate formation of sulfenic acids. Reaction with Pnucleophiles such as water-soluble phosphines appears to be an interesting method to transform sulfenic acid intermediates into more stable thiols (Figs. 7 and 8). Reaction with the C-nucleophile dimedone is a good method to efficiently trap sulfenic acid metabolites with formation of stable adducts (Figs. 6 and 7). Reaction with nucleophilic residues of proteins is responsible for the covalent binding of sulfenic acids to proteins that may be at the origin of pharmacological or toxicological effects of the parent xenobiotic.

Other fates of xenobiotic-derived sulfenic acid intermediates reported in the literature correspond to redox reactions occurring at the level of the $\mathrm{S}-\mathrm{OH}$ function. Further oxidations lead to sulfinic and sulfonic acids that are much more stable than sulfenic acids and that have been isolated as stable metabolites of several xenobiotics (see for instance Figs. 4 and 11). Reduction of the sulfenic acid function to the corresponding thiol could occur by several pathways. From the presently available literature data, the most frequently found pathway is reduction by GSH with the intermediate formation of a glutathionyl adduct RSSG (see for instance Fig. 22 and the above discussion). Other thiols gave the same result

A

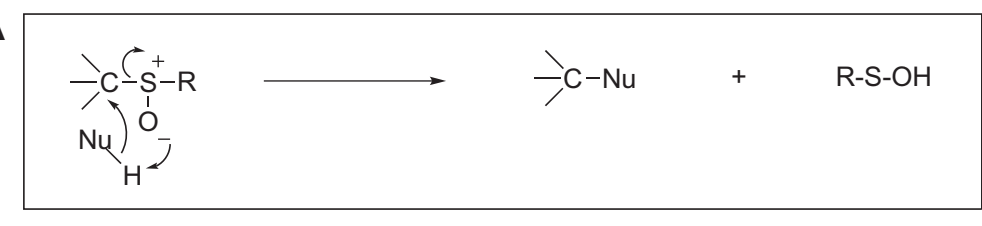

$\underset{I}{C}= \begin{cases}\mathrm{CH}_{2}-\mathrm{CH}_{2}=\mathrm{CH}_{2} \text { (diallylsulfoxide), } \mathrm{CH}_{2}-\mathrm{Ar} \text { (pantoprazole) } \\ \mathrm{C}-\mathrm{R} \text { (thioesters), } & \stackrel{\mathrm{C}-\mathrm{R}}{\text { O }} \text { (omeprazole) }\end{cases}$

$\mathrm{Nu}-\mathrm{H}=\mathrm{H}_{2} \mathrm{O}, \mathrm{GSH}$ or $\mathrm{N}$ (pyridine)

B

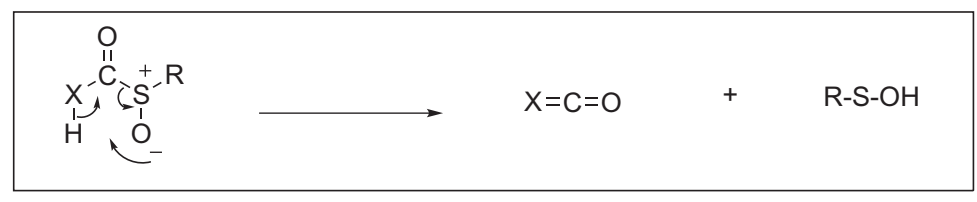

$$
\begin{aligned}
& X=R^{\prime} \mathrm{CH} \text { (fatty acid esters) } \\
& X=N R^{\prime} \quad \text { (glitazones) }
\end{aligned}
$$

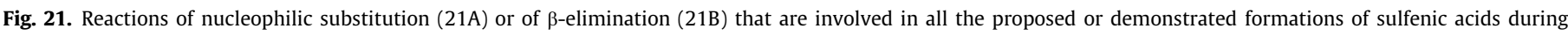
xenobiotic metabolism (if one excepts the S-hydroxylation of thiols). 


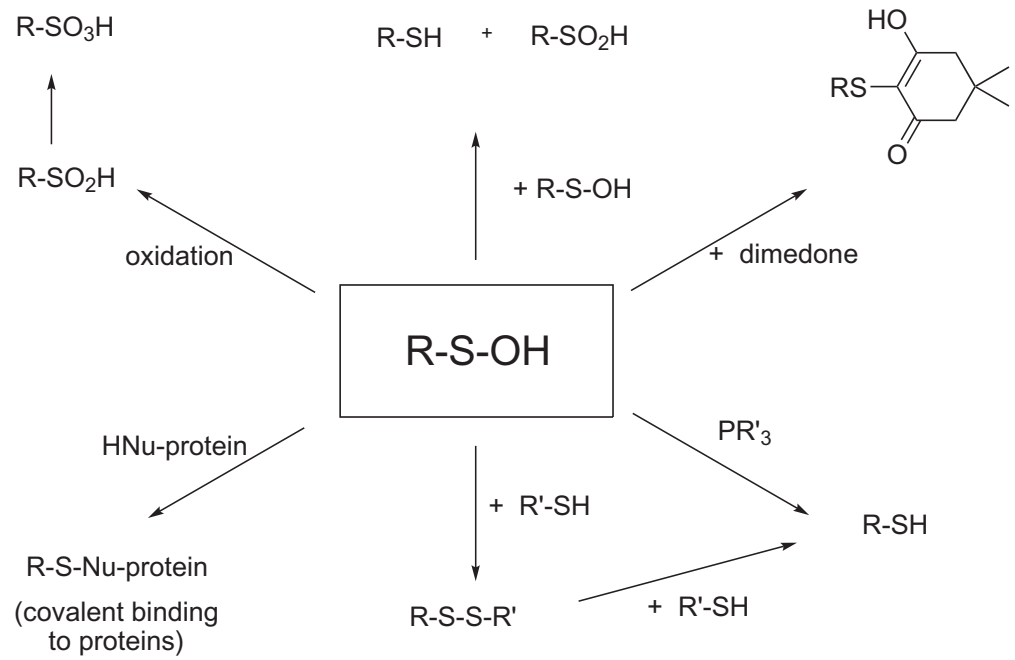

Fig. 22. Various possible fates of xenobiotic-derived sulfenic acid metabolites from literature data.

[26,30,31,34], and chemical reductants such as phosphines [31], $\mathrm{AsO}_{2}{ }^{-}$, and ascorbate (P. Dansette and D. Mansuy, unpublished results) were found to reduce the sulfenic acid intermediate derived from prasugrel into the corresponding thiol. Direct reduction with NADPH of sulfenic acid 22c, that was proposed to derive from the oxidation of 21c by recombinant P450 3A4 and cumyl hydroperoxide, also led to the corresponding thiol 24c [34]. Protein sulfenic acid intermediates have been reported to be recycled back to the thiol state by several enzymatic systems [5]. However, no data are presently available on possible enzymatic reduction of xenobiotic-derived sulfenic acid intermediates. This should be mainly due to the chemical unstability of sulfenic acids that makes very difficult the study of their possible reduction by enzymatic systems.

Another possible way of formation of thiols RSH and sulfinic acids $\mathrm{RSO}_{2} \mathrm{H}$ from sulfenic acids is the dismutation of sulfenic acids, as previously proposed for glitazone-derived sulfenic acids [34] (Fig. 12) and as shown for purine-6-sulfenic acid, a metabolite of the antineoplastic agent 6-thiopurine, that disproportionates to give 6-thiopurine and purine-6-sulfinic acid [51]. Formation of glutathionyl mixed disulfide adducts and/or sulfinic and sulfonic acid metabolites are a good indication but not a proof for intermediate formation of sulfenic acids. Trapping of these intermediates by dimedone and characterization of the corresponding stable dimedone adducts is a more direct evidence for their formation.

Formation of electrophilic sulfenic acid metabolites of xenobiotics should have important consequences in pharmacology and toxicology. However, few data are presently available on this subject in the literature, presumably because of the limited number of studies that have been published to establish the formation of sulfenic acids during xenobiotic metabolism and to discuss the fate of these intermediates. Reaction of sulfenic acid metabolites of omeprazole derivatives with cysteine residues of gastric $\mathrm{H}^{+} / \mathrm{K}^{+}$ATPase appears to lead to an inhibition of this protein which is at the origin of the pharmacological effects of these "prasole" produgs (Fig. 18) [46-48]. Sulfenic acid intermediates are formed during metabolism of the anti-thrombotic produgs, ticlopidine, clopidogrel and prasugrel (Figs. 6 and 7) [26,30,31]. The thiol metabolites deriving from their reduction have been proposed as the pharmacologically active species that are responsible for the inhibition of the P2Y12 platelet receptor after formation of a covalent disulfide bond with a cysteine residue of this protein [20,52]. Another possible mechanism for this inactivation of the P2Y12 receptor could be the formation of such a covalent bond from reaction of their sulfenic acid metabolites $\mathbf{1 0}$ and $\mathbf{1 6}$, or of the glutathionyl adducts $\mathbf{1 2}$ and $\mathbf{1 8}$ deriving from their reaction with GSH (Figs. 6 and 7) with a cysteine SH residue of the P2Y12 platelet receptor [26,31]. The latter mechanism remains to be established.

The inhibition of aldehyde dehydrogenase that is involved in the pharmacological effects of disulfiram appears to derive from a reaction of this enzyme with electrophilic metabolites of disulfiram such as $\mathbf{3 0}$ or $\mathbf{3 1}$ (Fig. 14) [17,36,37,53]. The sulfenic acid possibly formed in disulfiram metabolism (Fig. 14) could be another electrophilic species responsible for aldehyde dehydrogenase inactivation. Finally, cytochrome P450 inactivation observed during metabolic oxidation of spironolactone [14,54] (Fig. 4) appears to be due to electrophilic species formed by S-oxidation of the thiol metabolite, which could be the sulfenic acid itself or a thiyl radical intermediate [14].

Much less data are presently available about the role of xenobiotic-derived sulfenic acid metabolites in toxicology. Formation of sulfenic acid intermediates has been proposed in the metabolism of gitazones (Fig. 11) [34]. The secondary toxic effects found with some glitazones could be, at least in part, due to those electrophilic intermediates or to their S-oxide precursors and/or to their reaction products with GSH (Fig. 11), as all these species are electrophiles. Anyway, further studies are necessary to evaluate the possible roles of xenobiotic-derived sulfenic acid intermediates in toxicology.

\section{References}

[1] W.S. Allison, Acc. Chem. Res. 9 (1976) 293-299.

[2] A. Claiborne, H. Miller, D. Parsonage, R.P. Ross, FASEB J. 7 (15) (1993) 14831490.

[3] A. Claiborne, J.I. Yeh, T.C. Mallett, J. Luba, E.J. Crane 3rd, V. Charrier, D. Parsonage, Biochemistry 38 (47) (1999) 15407-15416.

[4] A. Claiborne, T.C. Mallett, J.I. Yeh, J. Luba, D. Parsonage, Adv. Protein. Chem. 58 (2001) 215-276.

[5] L.B. Poole, P.A. Karplus, A. Claiborne, Annu. Rev. Pharmacol. Toxicol. 44 (2004) 325-347.

[6] C. Jacob, I. Knight, P.G. Winyard, Biol. Chem. 387 (10-11) (2006) 1385-1397.

[7] L.V. Benitez, W.S. Allison, J. Biol. Chem. 249 (19) (1974) 6234-6243.

[8] L.B. Poole, B.B. Zeng, S.A. Knaggs, M. Yakubu, S.B. King, Bioconjugate Chem. 16 (6) (2005) 1624-1628.

[9] H.R. Ellis, L.B. Poole, Biochemistry 36 (48) (1997) 15013-15018.

[10] B. Testa, S.D. Kramer, Chem. Biodivers. 4 (3) (2007) 257-405.

[11] B. Testa, S.D. Kramer, Chem. Biodivers. 5 (11) (2008) 2171-2336.

[12] B. Testa, S.D. Kramer, Chem. Biodivers. 6 (5) (2009) 591-684.

[13] K.L. Taylor, D.M. Ziegler, Biochem. Pharmacol. 36 (1) (1987) 141-146.

[14] C.J. Decker, M.S. Rashed, T.A. Baillie, D. Maltby, M.A. Correia, Biochemistry 28 (12) (1989) 5128-5136.

[15] C.J. Decker, J.R. Cashman, K. Sugiyama, D. Maltby, M.A. Correia, Res. Toxicol. 4 (6) (1991) 669-677. 
[16] D.C. Kossor, S. Kominami, S. Takemori, H.D. Colby, Mol. Pharmacol. 40 (2) (1991) 321-325.

[17] B.W. Hart, M.D. Faiman, Biochem. Pharmacol. 43 (3) (1992) 403-406.

[18] K. Yoneda, R. Iwamura, H. Kishi, Y. Mizukami, K. Mogami, S. Kobayashi, Br. J. Pharmacol. 142 (3) (2004) 551-557.

[19] J.M. Pereillo, M. Maftouh, A. Andrieu, M.F. Uzabiaga, O. Fedeli, P. Savi, M. Pascal, J.M. Herbert, J.P. Maffrand, C. Picard, Drug Metab. Dispos. 30 (11) (2002) 1288-1295.

[20] C. Gachet, Thromb. Haemost. 99 (3) (2008) 466-472.

[21] A. Tuong, A. Bouyssou, J. Paret, T.G. Cuong, Eur. J. Drug Metab. Pharmacokinet. 6 (2) (1981) 91-98.

[22] N.T. Ha-Duong, S. Dijols, A.C. Macherey, J.A. Goldstein, P.M. Dansette, D. Mansuy, Biochemistry 40 (40) (2001) 12112-12122.

[23] D.K. Dalvie, A.S. Kalgutkar, S.C. Khojasteh-Bakht, Chem. Res. Toxicol. 15 (3) (2002) 269-299.

[24] N.A. Farid, A. Kurihara, S.A. Wrighton, J. Clin. Pharmacol. 50 (2) (2010) 126142.

[25] M. Kazui, Y. Nishiya, T. Ishizuka, K. Hagihara, N.A. Farid, O. Okazaki, T. Ikeda, A. Kurihara, Drug Metab. Dispos. 38 (1) (2010) 92-99.

[26] P.M. Dansette, J. Libraire, G. Bertho, D. Mansuy, Chem. Res. Toxicol. 22 (2) (2009) 369-373.

[27] A. Sugidachi, F. Asai, K. Yoneda, R. Iwamura, T. Ogawa, K. Otsuguro, H. Koike, Br. J. Pharmacol. 132 (1) (2001) 47-54.

[28] M. Hasegawa, A. Sugidachi, T. Ogawa, T. Isobe, J.A. Jakubowski, F. Asai, Thromb. Haemost. 94 (3) (2005) 593-598.

[29] E.T. Williams, K.O. Jones, G.D. Ponsler, S.M. Lowery, E.J. Perkins, S.A. Wrighton, K.J. Ruterbories, M. Kazui, N.A. Farid, Drug Metab. Dispos. 36 (7) (2008) 12271232.

[30] K. Hagihara, M. Kazui, A. Kurihara, H. Iwabuchi, M. Ishikawa, H. Kobayashi, N. Tanaka, O. Okazaki, N.A. Farid, T. Ikeda, Drug Metab. Dispos. 38 (6) (2010) 898904.

[31] P.M. Dansette, S. Thebault, G. Bertho, D. Mansuy, Chem. Res. Toxicol. 23 (2010) 1268-1274.

[32] K. Goto, K. Shimada, M. Nagahama, R. Okazaki, T. Kawashima, Chem. Lett. 32 (11) (2003) 1080-1081.
[33] B.V. Karanam, C.E. Hop, D.Q. Liu, M. Wallace, D. Dean, H. Satoh, M. Komuro, K. Awano, S.H. Vincent, Drug Metab. Dispos. 32 (9) (2004) 1015-1022.

[34] V.B. Reddy, B.V. Karanam, W.L. Gruber, M.A. Wallace, S.H. Vincent, R.B. Franklin, T.A. Baillie, Chem. Res. Toxicol. 18 (5) (2005) 880-888.

[35] K. He, R.E. Talaat, W.F. Pool, M.D. Reily, J.E. Reed, A.J. Bridges, T.F. Woolf, Drug Metab. Dispos. 32 (6) (2004) 639-646

[36] L. Jin, M.R. Davis, P. Hu, T.A. Baillie, Chem. Res. Toxicol. 7 (4) (1994) $526-$ 533.

37] P. Hu, L. Jin, T.A. Baillie, J. Pharmacol. Exp. Ther. 281 (2) (1997) 611-617.

[38] B.W. Hart, J.J. Yourick, M.D. Faiman, Alcohol 7 (2) (1990) 165-169.

[39] B.W. Hart, M.D. Faiman, Biochem. Pharmacol. 49 (2) (1995) 157-163.

[40] G.B. Quistad, S.E. Sparks, J.E. Casida, Life Sci. 55 (20) (1994) 1537-1544

[41] R.E. Staub, S.E. Sparks, G.B. Quistad, J.E. Casida, Chem. Res. Toxicol. 8 (8) (1995) 1063-1069.

[42] N. Shirane, Z. Sui, J.A. Peterson, P.R. Ortiz de Montellano, Biochemistry 32 (49) (1993) 13732-13741.

[43] P.C. Feng, R.T. Solsten, Xenobiotica 21 (10) (1991) 1265-1271.

[44] R.E. Pearce, J.S. Leeder, G.L. Kearns, Drug Metab. Dispos. 34 (6) (2006) 1035 1040.

[45] F. Chanoine, C. Grenot, N. Sellier, W.E. Barrett, R.M. Thompson, A.F. Fentiman, J.R. Nixon, R. Goyer, J.L. Junien, Drug Metab. Dispos. 15 (6) (1987) 868-876.

[46] M.H. Potashman, M.E. Duggan, J. Med. Chem. 52 (5) (2009) 1231-1246.

[47] J.M. Shin, Y.M. Cho, G. Sachs, J. Am. Chem. Soc. 126 (25) (2004) 7800-7811.

[48] M.F. Tutunji, A.M. Qaisi, B.I. El-Eswed, L.F. Tutunji, J. Pharm. Sci. 96 (1) (2007) 196-208.

49] D. Zhong, Z Xie, X. Chen, J. Pharm. Pharmacol. 57 (3) (2005) 341-349.

[50] L. Jin, T.A. Baillie, Chem. Res. Toxicol. 10 (3) (1997) 318-327.

[51] R.T. Abraham, L.M. Benson, I. Jardine, J. Med. Chem. 26 (10) (1983) 1523-1526

[52] I. Algaier, J.A. Jakubowski, F. Asai, I. von Kugelgen, J. Thromb. Haemost. 6 (11) (2008) 1908-1914.

[53] B.W. Hart, M.D. Faiman, Alcohol. Clin. Exp. Res. 18 (2) (1994) 340-345.

[54] H.D. Colby, J.P. O’Donnell, N.L. Flowers, D.C. Kossor, P.B. Johnson, M. Levitt, Toxicology 67 (2) (1991) 143-154. 